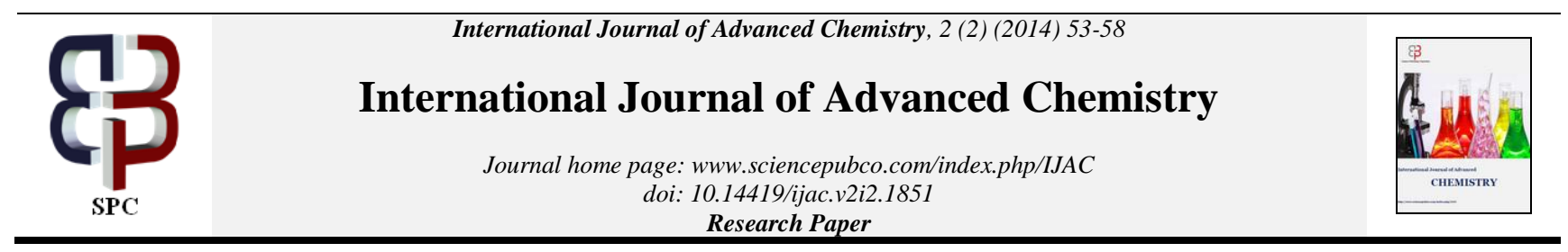

\title{
Green synthesis and antibacterial evaluation of some 2-pyrazoline derivatives
}

\author{
N.Santhi ${ }^{1 *}$, M.Emayavaramban $^{2}$, C.Gopi $^{2}$, C.Manivannan $^{2}$, A.Raguraman $^{2}$ \\ ${ }^{1}$ Department of chemistry, government arts college, c. mutlur, Chidambaram, tamilnadu, India \\ ${ }^{2}$ Department of chemistry, manonmaniam sundaranar university, tirunelveli-627012, tamilnadu, India \\ *Corresponding author E-mail: nsaanthi@gmail.com
}

\begin{abstract}
A Chalcone (3) was prepared by the reaction of 4-methylbenzaldehyde (1) with 4-methylacetophenone (2) in methanolic sodium hydroxide result under ultrasonic irradiation in the water bath of a ultrasonic cleaner at room temperature. Treatment of this chalcone with thiosemicarbazide / semicarbazide hydrochloride / benzhydrazide / benzenesulphonyl hydrazide / phenylhydrazine hydrochloride managed the comparing 2-pyrazoline (4-8) in great yields. All the new mixes have been described by IR, 1H-NMR, 13CNMR ghostly information. All the target mixes were assessed for their in-vitro against antifungal in examination with as reference pill.
\end{abstract}

Keywords: 4-Methylbenzaldehyde, 4-Methyl Acetophenone, Ultrasonic Irradiation, Chalcone, 2-Pyrazoline, Antibacterial.

\section{Introduction}

Chalcones are natural biocides [1] and are well known intermediates for synthesizing various heterocycles. Introduction of halogen into the benzenoid part of $\alpha, \beta$-unsaturated ketones enhances the biological activity appreciably [2]. Presence of enone functionality in chalcone confers the antibiotic activity [3] and [4]. Chalcone are useful synthons in the synthesis of a large number of bioactive molecules such as pyrazolines, isoxazoles etc.The pyrazole ring is a prominent structural motif found in numerous pharmaceutically active compounds. 2-Pyrazolines display a broad spectrum of potential pharmacological activities and are present in a number of pharmacologically active molecules such as phenazone/ amidopyrene/ methampyrone (analgesic and antipyretic), azolid/ tandearil (anti-inflammatory), indoxacarb (insecticide) and anturane (uricosuric).Changes in their structure have offered a high degree of diversity that has proven useful for the development of new therapeutic agents having improved potency and lesser toxicity.

The title compound pyrazoline is five-membered heterocyclic having two adjacent nitrogen atoms within the ring. It has only one endocyclic double bond and is basic in nature [5].It plays a crucial role in the development of theory in heterocyclic chemistry and is also extensively used as useful synthons in organic synthesis [6]. Pyrazolines have been reported to show a broad spectrum of biological activities including antibacterial [7] antifungal [8],anti-inflammatory [9], analgesic [10], antipyretic [11], insecticidal [12], diuretic [13], cardiovascular [14] and antidepressant activities [15]. Recent trends in organic synthesis utilize a nonconventional technique such as ultrasound (sonochemistry), which has proved to have many advantages. High-power ultrasound can generate cavitations within a liquid that providing a source of energy which can be used to enhance a wide range of chemical processes. Sonochemistry concentrates on the applications in organic synthesis where, ultrasound seems to provide a distinct al ternative to other, more traditional, techniques of improving reaction rates and product yields.

Ultrasound waves are known for their wide applications in various fields like life sciences, medical, cleaning, sonar, electronics, agriculture, oceanography, material science etc. [16], [20]. Recently, ultrasound has been utilized to accelerate a wide number of synthetically useful organic reactions. [21], [22] Further, these waves prove to be important in synthetic organic chemistry [23], [25] by lowering the reaction temperature and reaction time [26]. In addition to the field of organic chemistry, sonochemistry has also been used in the preparation of micro and Nanomaterials, i.e., protein microspheres [27]. Encouraged by these results, it was planned to synthesize 1, 3, 5-trisubstituted Pyrazoline derivatives under ultrasonic irradiation and the synthesized compounds were screened for their biological activities.

\section{Chemistry}

In the present work, (E)-1,3-di(p-tolyl)prop-2-en-1-one (3) was prepared by reaction of 4-methylacetophenone (2) with 4methylbenzaldehyde (1) in dilute ethanolic sodium hydroxide solution under ultrasonic irradiation in the water bath of an ultrasonic cleaner at room temperature in accordance with the method described in the literature. Ultrasound irradiation has been increasingly used in organic synthesis in last three decades. Large number of organic reactions can be carried out in higher yield, shorter reaction time and milder conditions under ultrasonic irradiation. It was observed that the reaction time decreased considerably and the yields of the products promoted in the presence of ultrasonic irradiation. Thus, ultrasound was found to have beneficial effect on the synthesis of chalcone and pyrazoline derivatives in which decrease time of above reactions from 8 to $10 \mathrm{~h}$ in conventional procedure to less than $1 \mathrm{~h}$, also, a noticeable improvement in yields of reactions under ultrasonic irradiations. The synthetic route of compound (3), (4), (5), (6), (7), (8) is outlined in Scheme 
1. The physical data along with reaction time and yield of synthe- $\quad$ sized compounds were reported in Table 1.
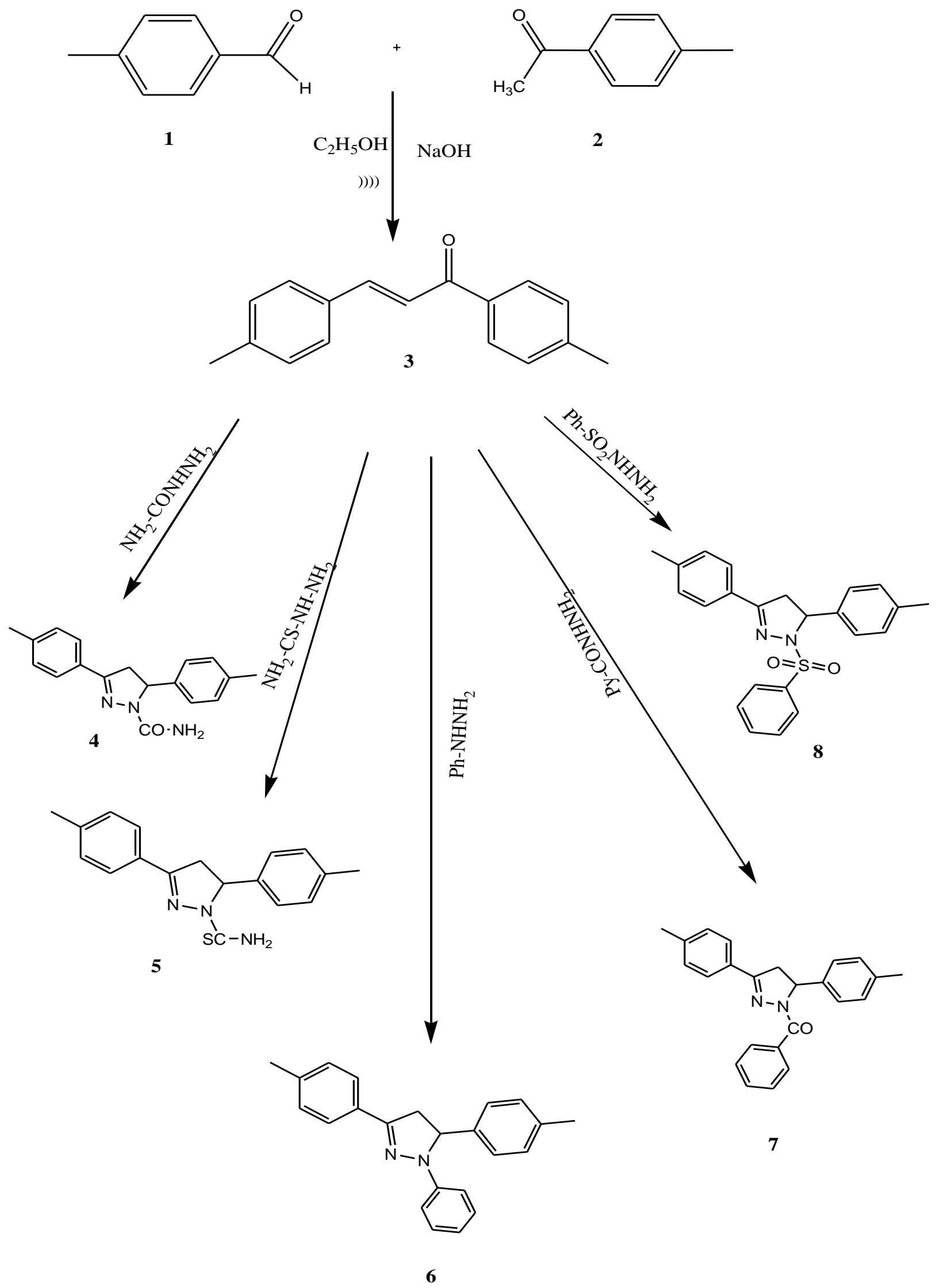

Scheme. 1: Synthesis of Chalcone and pyrazoline derivatives (3-8) 


\section{Results and discussion}

Formation of the synthesized derivatives 3-8 were confirmed on the basis of their IR and 1H-NMR and 13C NMR data. Selected diagnostic bands of the IR spectra of the Chalcone (3) showed useful information about the structure of the compounds. The IR spectra for synthesized chalcone observed the shifting of absorption band of carbonyl group for the two reactants 4-methyl acetophenone and 4-methyl benzaldehyde is $1670 \mathrm{~cm}-1$ to lower wave number $1650 \mathrm{~cm}-1$, which is a strong evidence for the formation of conjugated enone of chalcone[28]. Other strong bands appeared at $1597 \mathrm{~cm}-1$, corresponding to $\mathrm{C}=\mathrm{C}$ of the enone and aromatic rings, also the disappearance of aldehydic $(\mathrm{CH})$ bands is a good evidence for the formation of chalcones. The IR spectra of condensed product 4-8 displayed disappearance of the characteristic absorption at $1650 \mathrm{~cm}-1$ for $-\mathrm{C}=\mathrm{O}$ of conjugated carbonyl and presence of characteristic absorption band at 1568-1597 due to $\mathrm{C}=\mathrm{N}$ of pyrazoline in the IR spectrum. Synthesized compounds 48 showed weak $\mathrm{C}-\mathrm{H}$ stretching bands near 3024-3098 cm-1, C=C skeletal vibrations near $1469-1510 \mathrm{~cm}-1$ for aromatic and absorption around 2918-2923 cm-1 for aliphatic nature of compounds/substituents.

The $\mathrm{H}-\alpha$ and $\mathrm{H}-\beta$ protons of Chalcone (3) occur as two doublets in the ranges $7.49 \mathrm{ppm}(\mathrm{H}-\alpha)$ and $7.78 \mathrm{ppm}(\mathrm{H}-\beta)$ in the $1 \mathrm{H}$ NMR spectra.1H-NMR spectra suggest, $7.49 \mathrm{ppm}$ the $\mathrm{C} \alpha-\mathrm{H}$ and 7.78 ppm $\mathrm{C} B-\mathrm{H}$ protons are considerably shifted downfield to the extent that they appear in the aromatic region 7.21-7.94. As a result, these protons can hardly be distinguished from those of the aromatic rings. This is probably associated with the joint deshielding resonance and anisotropic effects of the groups bonded to Bcarbon atom, and the disappearance of the aldehydic proton 9-10 ppm is a good evidence for the formation of product.

The1H NMR spectra of products showed characteristics ABX system due to geminal-vicinal multiple coupling between 4-CH2 and 5-CH protons. The high field double doublet at $\delta$ 3.09-3.16 and $\delta 3.74-3.83$ due to HA and $\mathrm{HB}$ respectively of C-4 protons and low field $\delta$ 5.20-5.52 due to $\mathrm{Hx}$ at $\mathrm{C}-5$ are characteristics signals due to vicinal coupling with the two magnetically nonequivalent protons of methylene group at position 4 of the pyrazolines ring. In all the compounds absorption as multiplet at $\delta$ 6.75-7.94 was assigned to aromatic protons.

13C-NMR spectra of all compounds were recorded in DMSO and $\mathrm{CDCl} 3$, spectral signals which are in good agreement with the probable structures. The most important features of 13C-NMR spectra of synthesized chalcone is the $\beta$ - carbon atom resonance at $142.04 \mathrm{ppm}$ which appeared down field of $\alpha$-carbon atom at 118.7 ppm because of mesomeric deshielding effect of the carbonyl group [29].

The C4 and C5 carbon of pyrazolines resonated at 43.0-43.7 and 59.5-64.2 ppm, respectively. The carbon of - $\mathrm{CH} 3$ in all compounds resonates at $21.4-30.3 \mathrm{ppm}$, respectively. The carbon of $(\mathrm{C}=\mathrm{O})$ displayed signals at 155.4-187.7. All the compounds showed signal at 113.3-141.8 ppm were assigned to the aromatic carbon. All the compounds 3-8 showed signals at 151.01- 157.2 ppm assigned to $(\mathrm{C}=\mathrm{N})$.

\section{Biological activity}

\subsection{Antibacterial studies}

The synthesized chalcone and pyrazoline derivatives were screened for the antibacterial activity against three Gram-positive bacteria viz., Streptococcus pyogenes, Bacillus subtilis and Staphylococcus aureus and two Gram-negative bacteria viz., Escherichia coli and Pseudomonas aeruginosa by using the cup plate method [30], [32]. Streptomycin was used as reference standard for comparing the results. The antibacterial activity of the pyrazoline derivatives are shown in Fig: 1 for Plates 1-5 and the zone of inhibition values are given Table-2. The Clustered column Fig 3 Showed that Chalcone and pyrazoline
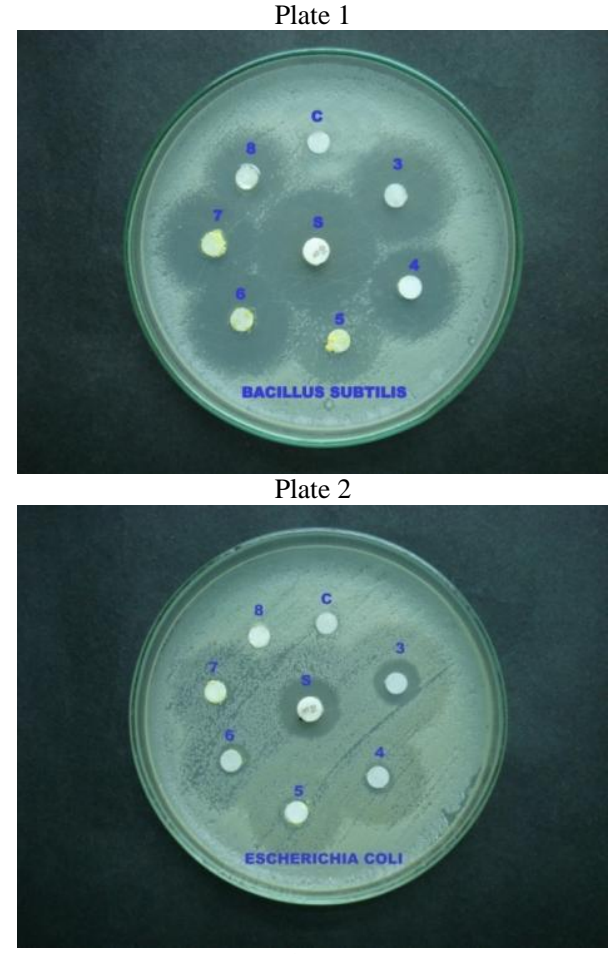

Plate 3

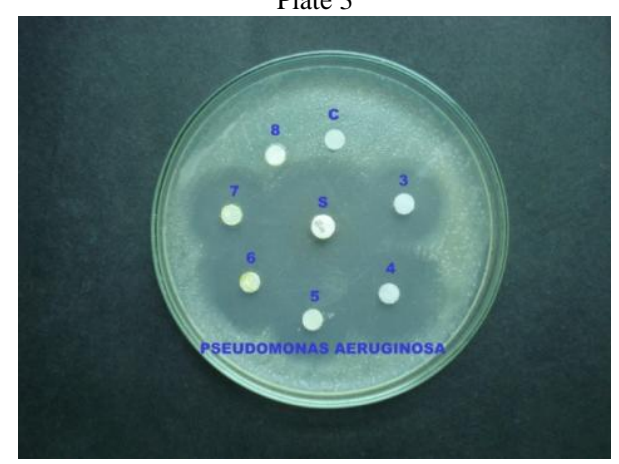

Plate 4

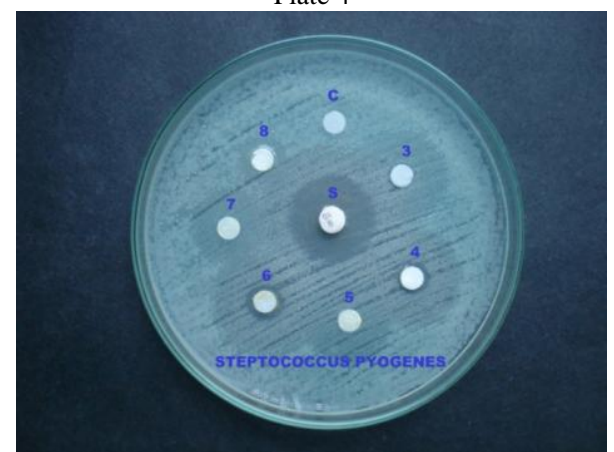

Plate 5

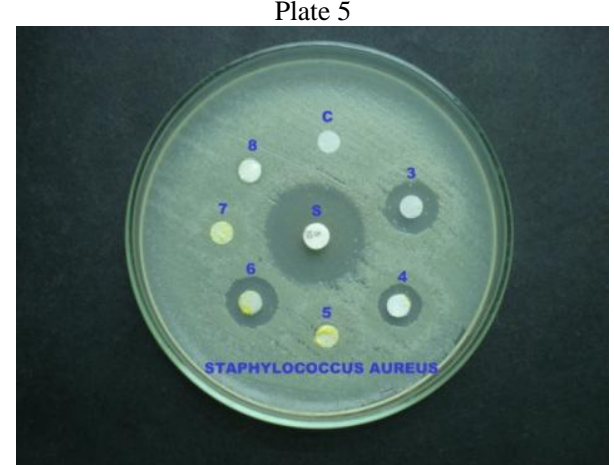

Fig. 1: Antibacterial activities by zone of inhibition of chalcone and pyrazoline derivatives (3-8)

Derivatives of (3) to (8) possess significant activity almost equipotent with the standard Streptomycin against Gram +ve and Gram - 
ve pathogenic organism. Thus the substituents place a vital role in imparting enhanced antibacterial activity to the compounds.

The screening results indicate that compound (4) was found to be active against S. aureus. Compounds (3) and (6) were found to moderately active be active against $\mathrm{S}$. aureus, whereas compounds (5), (7) and (8) were found to be inactive be active against $S$. aureus. Compounds (3), (4), (6) and (7) were found to be active against B. subtilis.Compounds (5) and (8) were found to be moderately active against B. subtilis. Compounds (6) and (7) were found to be moderately active against E. coli, whereas (3), (4) and (5) were found to be less active against E. coli. Compound (7) was found to be active against S.pyogenes. Compound (4) was found to be moderately active against S.pyogenes.whereas (6) and (8) were found to be less active against S.pyogenes. Compounds (4) and (5) were found to moderately active be active against P.aeruginosa. Whereas compounds (3) and (7) were found to be less active be active against $P$.aeruginosa.

The minimam inhibitory concentrations of the strongly active compounds were also measured. The antimicrobial activity of the synthesized pyrazolines derivatives (4) and (7) were examined by two fold serial dilution methods. Bacterial strains,viz. Bacillus subtilis,Escherichia coli, Pseudomonas aeruginosa, Staphylococcus aureus and Streptococcus pyogenes species. In the present study, DMSO is used as control, while Streptomycin are used as standards for bacterial strain. The representative photographs of serial dilution methods are depicted in Figure 2 for plates 6-8.

Antibacterial activity of all synthesized pyrazolines was measured by serial dilution method, and the MICs are presented in Table 3 . From Table 3, compounds (4) and (7) showed the growth inhibitory concentration against the tested organism fall in the range of 12.5 to $200 \mu \mathrm{g} / \mathrm{mL}$. Compounds (4) and (7) showed the inhibition against Pseudomonas aeruginosa, Staphylococcus aureus, and Streptococcus pyogenes bacterial strains in the range from 12.5 to $100 \mu \mathrm{g} / \mathrm{ml}$.

\section{Conclusion}

In conclusion, ultrasonic irradiation synthesis provides an excellent approach for the safe, rapid, economical,environment friendly, non-hazardous, and easierwork-up procedure and good yield synthesis of pharmacologically important heterocyclic compounds. All synthesized pyrazoline derivatives showed moderate to good antibacterial activities compared with standard drugs.

\section{Experimental protocols}

Melting points were determined by open capillary method and are uncorrected. The IR spectra (in $\mathrm{KBr}$ pellets) were recorded on a Shimadzu FT-IR 157 spectrophotometer. ${ }^{1} \mathrm{H}$ NMR spectra were recorded either on a Bruker or $300 \mathrm{MHz}$ or $400 \mathrm{MHz}$ NMR spectrometer using TMS as an internal standard. The purity of the compounds was checked by thin layer chromatography (TLC) on silica gel plate using petroleum ether and ethyl acetate.

\subsection{Procedure for the preparation of (E)-1, 3-dip- tolylprop-2-en-1-one (3)}

4-methylbenzaldehyde (2.5 mmole), 4-methylacetophenone (2.5mmol), 95\% Ethanol $(20 \mathrm{~mL})$ and $2 \mathrm{~N} \mathrm{NaOH}(3 \mathrm{~mL})$ were taken into a $100 \mathrm{~mL}$ conical flask. The mixture was irradiated by an ultrasonic generator in a water-bath at $30-35^{\circ} \mathrm{C}$ for $3 \mathrm{~min}$. The product was filtered with suction on a Buchner funnel, washed with cold water until the washings were neutral to litmus and then with ice cold ethanol. The crude product was recrystallized from ethanolto afford greenish yellow shiny crystals. Yield: 71.81\%; m.p. $112{ }^{\circ}$ C. M.F; $\mathrm{C}_{17} \mathrm{H}_{16} \mathrm{O}$; IR (KBr) vmax cm${ }^{-1}: 3,060(\mathrm{Ar}-\mathrm{H})$, 2,927 (C-H), 1,650 (C=O), 1,505 (C=C); ${ }^{1} \mathrm{H}-\mathrm{NMR}$ (DMSO-d6) ( $\delta / \mathrm{ppm}): 7.78(\mathrm{~d}, 1 \mathrm{H}, \mathrm{C}=\mathrm{CH}), 7.49(\mathrm{~d}, 1 \mathrm{H}, \mathrm{CO}=\mathrm{CH}), 2.44(\mathrm{~s}, 6 \mathrm{H}$,

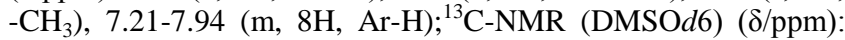
187.70(C=O), 142.70(C $\beta), \quad 126.0-141.03(\mathrm{Ar}-\mathrm{C}) \quad, \quad 118.7(\mathrm{C} \alpha)$, $19.07\left(\mathrm{CH}_{3}\right)$.
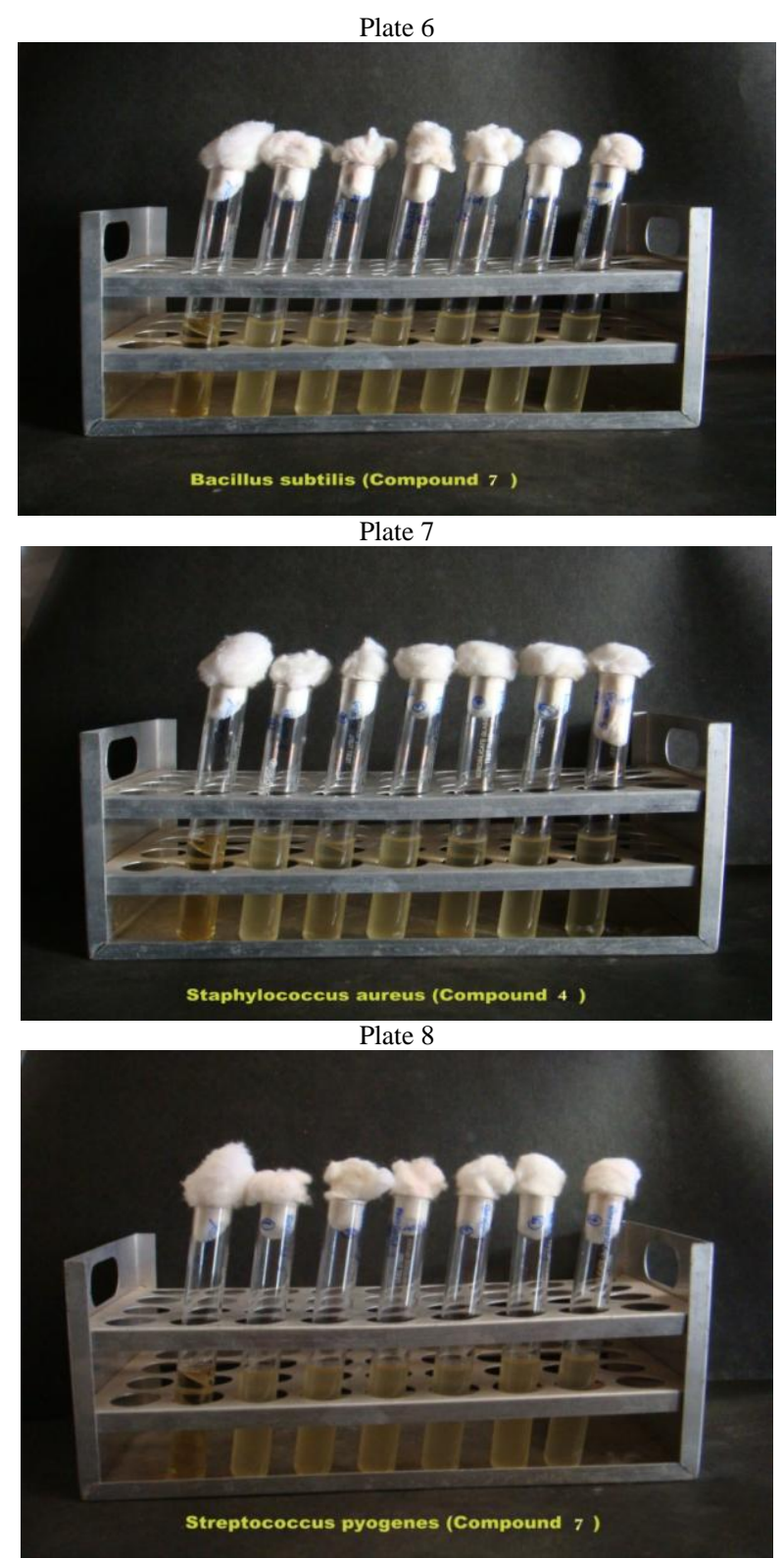

Fig. 2: The antibacterial Activities of pyrazoline derivatives by Serial Dilution Method. 


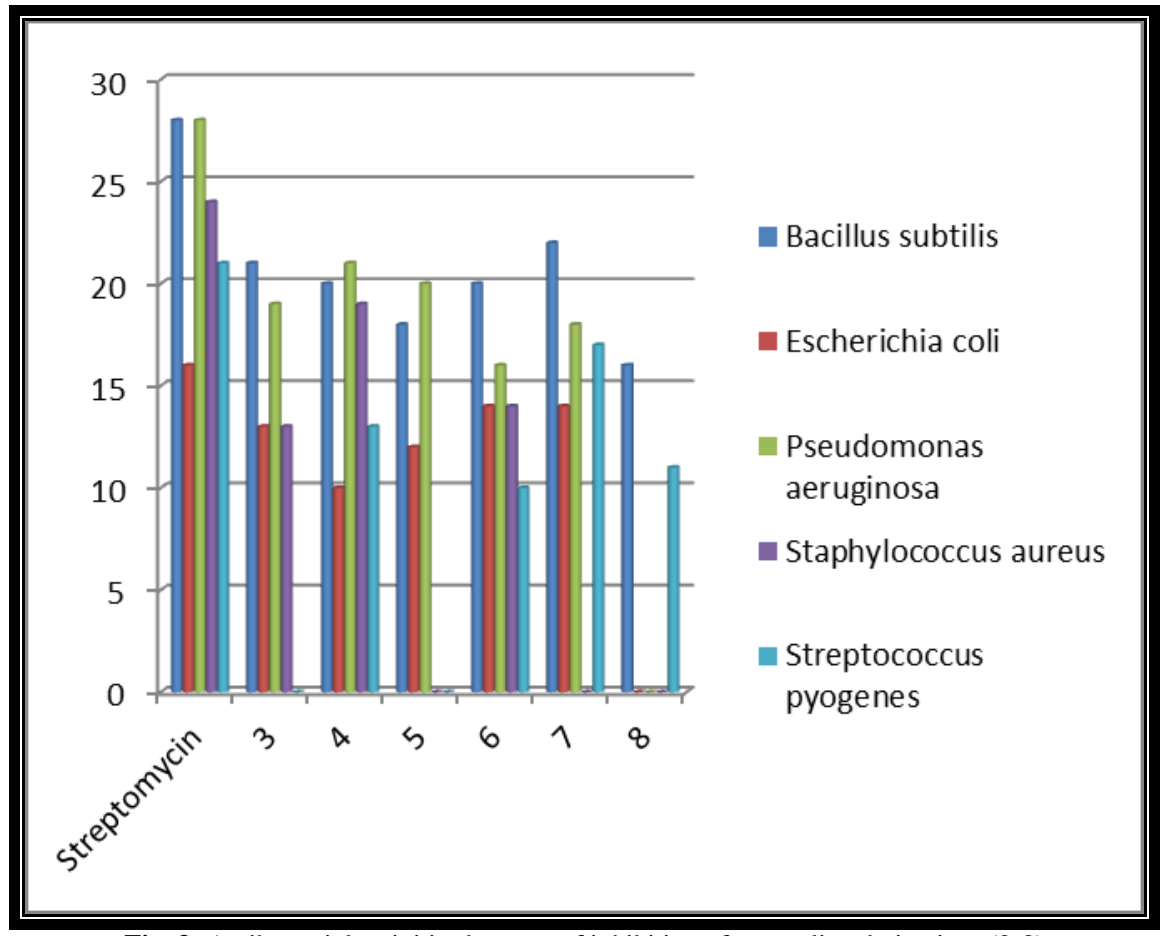

Fig. 3: Antibacterial activities by zone of inhibition of pyrazoline derivatives (3-8)

\subsection{Procedure for the preparation of 4, 5-dihydro-3, 5- dip-tolylpyrazole-1-carboxamide (4)}

(E)-1, 3-dip-tolylprop-2-en-1-one, (2.5 mmole), semicarbazide hydrochloride, $(2.5 \mathrm{mmole})$ and gl acetic acid $(20 \mathrm{~mL})$ were taken intoa $100 \mathrm{~mL}$ conical flask. This reaction flask was suspended at the center of the ultrasonic cleaning-bath to get the maximum ultrasound energy and sonicated until crystals appeared or starting chalcone disappeared. The reaction-mixture was poured into crushed ice and left overnight. The precipitate was separated by filtration, washed well with water, dried and recrystallized from ethanol to afford yellow coloured crystals. Yield: 70\%; m.p. 152 ${ }^{\circ} \mathrm{C}$; M.F; $\mathrm{C}_{18} \mathrm{H}_{19} \mathrm{~N}_{3} \mathrm{O}$; IR (KBr) vmax cm ${ }^{-1}: 3,479$ (NH), 3,024 (Ar$\mathrm{H}), 2,921(\mathrm{C}-\mathrm{H}), 1,589(\mathrm{HC}=\mathrm{N}), 1,678(\mathrm{C}=\mathrm{O}) ;{ }^{1} \mathrm{H}-\mathrm{NMR}$ (DMSOd6) $(\delta / \mathrm{ppm}): 6.63\left(\mathrm{~s}, 2 \mathrm{H}, \mathrm{NH}_{2}\right), 7.16-7.62(\mathrm{~m}, 8 \mathrm{H}, \mathrm{Ar}-\mathrm{H}), 5.52$ (dd, 1H, Hx, ), 3.79 (dd, 1H, HA), $3.16(\mathrm{dd}, 1 \mathrm{H}, \mathrm{HB}), 2.34$ (s, 6H, $\left.\mathrm{CH}_{3}\right) ;{ }^{13} \mathrm{C}$ - NMR (DMSO-d6) $(\delta / \mathrm{ppm}): 155.39(\mathrm{C}=\mathrm{O}), 151.86$ $(\mathrm{C}=\mathrm{N}), 125.4-140.3(\mathrm{Ar}-\mathrm{C}), 59.77(\mathrm{CH}), 43.06\left(\mathrm{CH}_{2}\right), 21.50$ $\left(\mathrm{CH}_{3}\right)$.

6.3. Procedure for the preparation of 4, 5-dihydro-3, 5dip-tolylpyrazole-1-carbothioamide (5)

(E)-1, 3-dip-tolylprop-2-en-1-one,

(2.5 mmole) thiosemicarbazide, $(2.5$ mmole $)$ and gl. acetic acid $(20 \mathrm{~mL})$ were taken into a $100 \mathrm{~mL}$ conical flask. This reaction flask was suspended at the center of the ultrasonic cleaning-bath to get the maximum ultrasound energy and sonicated until crystals appeared or starting chalcone disappeared. The reaction-mixture was poured into crushed ice and left overnight. The precipitate was separated by filtration, washed well with water, dried and recrystallized from ethanol to afford yellow coloured crystals. Yield: 65\%; m.p. $188{ }^{\circ} \mathrm{C}$; M.F; $\mathrm{C}_{18} \mathrm{H}_{19} \mathrm{~N}_{3} \mathrm{~S}$; IR (KBr) vmax cm ${ }^{-1}: 3,479$ (NH), 3,037 $(\mathrm{Ar}-\mathrm{H}), 2,918(\mathrm{C}-\mathrm{H}), 1,568(\mathrm{HC}=\mathrm{N}), 1,266(\mathrm{C}=\mathrm{S}) ;{ }^{1} \mathrm{H}-\mathrm{NMR}$ (DMSO-d6) ( $\delta / \mathrm{ppm}): 7.27$ (s, 2H, NH2), 6.83-7.59 (m, 8H, Ar-H), 5.47 (dd, 1H, Hx,), 3.74 (dd, 1H, HA), 3.14 (dd, 1H, HB), 2.39 (s, $\left.\mathrm{CH}_{3}\right) ;{ }^{13} \mathrm{C}$ - NMR (DMSO- 66$)(\delta / \mathrm{ppm}): 170.52(\mathrm{C}=\mathrm{S}), 151.92$ $(\mathrm{C}=\mathrm{N}), 114.26-140.35(\mathrm{Ar}-\mathrm{C}), 59.54(\mathrm{CH}), 43.0\left(\mathrm{CH}_{2}\right), 21.44$ $\left(\mathrm{CH}_{3}\right)$.
6.4. Procedure for the preparation of 4, 5-dihydro-1phenyl-3, 5-dip-tolyl-1H-pyrazole (6)

(E)-1, 3-dip-tolylprop-2-en-1-one, (2.5 mmole), phenylhydrazine hydrochloride $(2.5 \mathrm{mmole})$ and gl. acetic acid $(20 \mathrm{~mL})$ were taken into $100 \mathrm{~mL}$ conical flask. This reaction flask was suspended at the center of the ultrasonic cleaning-bath to get the maximum ultrasound energy and sonicated until crystals appeared or starting chalcone disappeared. The reaction-mixture was poured into crushed ice and left overnight. The precipitate was separated by filtration, washed well with water, dried and recrystallized from ethanol to afford yellow coloured crystals. Yield: 78\%; m.p. 225 ${ }^{\circ} \mathrm{C} ; \mathrm{M} . \mathrm{F} ; \mathrm{C}_{23} \mathrm{H}_{22} \mathrm{~N}_{2}$; IR (KBr) vmax cm ${ }^{-1}: 3,077$ (Ar-H), 2,921 (C$\mathrm{H}), 1,578(\mathrm{HC}=\mathrm{N}) ;{ }^{1} \mathrm{H}-\mathrm{NMR}$ (DMSO- $\left.d 6\right)(\delta / \mathrm{ppm}): 6.75-7.62(\mathrm{~m}$, $13 \mathrm{H}, \mathrm{Ar}-\mathrm{H}), 5.21$ (dd, 1H, Hx), $3.80(\mathrm{dd}, 1 \mathrm{H}, \mathrm{HA}), 3.10(\mathrm{dd}, 1 \mathrm{H}$, $\mathrm{H} B), 2.35\left(\mathrm{~s}, \mathrm{CH}_{3}\right) ;{ }^{13} \mathrm{C}-\mathrm{NMR}$ (DMSO-d6) $(\delta / \mathrm{ppm}): 151.01$ $(\mathrm{C}=\mathrm{N}), 13.29-139.74(\mathrm{Ar}-\mathrm{C}), 64.22(\mathrm{CH}), 43.73\left(\mathrm{CH}_{2}\right), 29.71$ $\left(\mathrm{CH}_{3}\right)$.

6.5. Procedure for the preparation of $(4,5$-dihydro-3, 5dip-tolylpyrazol-1-yl)(phenyl)methanone (7)

(E)-1, 3-dip-tolylprop-2-en-1-one (2.5 mmole), benzhydrazide(2.5 mmole) and gl. acetic acid $(20 \mathrm{~mL})$ were taken into a $100 \mathrm{~mL}$ conical flask. This reaction flask was suspended at the center of the ultrasonic cleaning-bath to get the maximum ultrasound energy and sonicated until crystals appeared or starting chalcone disappeared. The reaction-mixture was poured into crushed ice and left overnight. The precipitate was separated by filtration, washed well with water, dried and recrystallized from ethanol to afford yellow coloured crystals. Yield: 78\%; m.p. $222{ }^{\circ} \mathrm{C}$; M.F; $\mathrm{C}_{24} \mathrm{H}_{22} \mathrm{~N}_{2} \mathrm{O}$; IR (KBr) vmax cm $\mathrm{cm}^{-1}: 3,098(\mathrm{Ar}-\mathrm{H}), 2,923(\mathrm{C}-\mathrm{H})$, 1,592 $(\mathrm{HC}=\mathrm{N}) ;{ }^{1} \mathrm{H}-\mathrm{NMR}$ (DMSO- $\left.d 6\right)(\delta / \mathrm{ppm}): 6.76-7.62(\mathrm{~m}$, $13 \mathrm{H}, \mathrm{Ar}-\mathrm{H}), 5.20$ (dd, 1H, Hx), 3.78 (dd, 1H, HA), 3.09 (dd, $1 \mathrm{H}$, $\mathrm{HB}), 2.37\left(\mathrm{~s}, \mathrm{CH}_{3}\right) ;{ }^{13} \mathrm{C}-\mathrm{NMR}$ (DMSO-d6) $(\delta / \mathrm{ppm}): 176.47$ $(\mathrm{C}=\mathrm{O}), 156.03(\mathrm{C}=\mathrm{N}), 129.91-141.80(\mathrm{Ar}-\mathrm{C}), 62.77(\mathrm{CH}), 43.01$ $\left(\mathrm{CH}_{2}\right), 21.60\left(\mathrm{CH}_{3}\right)$.

6.6. Procedure for the preparation of 3, 5-bis (4methylphenyl)-1-(phenylsulfonyl)-4, 5-dihydro-1Hpyrazole (8) 
(E)-1, 3-dip-tolylprop-2-en-1-one, (2.5mmole), benzene sulphonylhydrazide $(2.5 \mathrm{mmole})$ and gl. acetic acid $(20 \mathrm{~mL})$ were taken intoa $100 \mathrm{~mL}$ conical flask. This reaction flask was suspended at the center of the ultrasonic cleaning-bath to get the maximum ultrasound energy and sonicated until crystals appeared or starting chalcone disappeared. The reaction-mixture was poured into crushed ice and left overnight. The precipitate was separated by filtration, washed well with water, dried and recrystallized from ethanol to afford yellow coloured crystals. Yield: 86\%; m.p. $143{ }^{\circ} \mathrm{C}$; M.F; $\mathrm{C}_{23} \mathrm{H}_{22} \mathrm{~N}_{2} \mathrm{O}_{2} \mathrm{~S}$; IR (KBr) vmax $\mathrm{cm}^{-1}$ : 3,056 (Ar-H), 2,921 (C-H), 1,597 ( $\mathrm{HC}=\mathrm{N}), 1,323(\mathrm{O}=\mathrm{S}=\mathrm{O}) ;{ }^{1} \mathrm{H}-\mathrm{NMR}$ (DMSO-

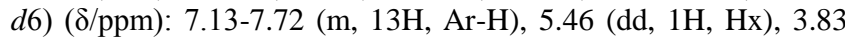
(dd, 1H, HA), $3.10(\mathrm{dd}, 1 \mathrm{H}, \mathrm{HB}), 2.41\left(\mathrm{~s}, \mathrm{CH}_{3}\right) ;{ }^{13} \mathrm{C}-\mathrm{NMR}$ $(\mathrm{DMSO}-d 6)(\delta / \mathrm{ppm}): 157.20(\mathrm{C}=\mathrm{N}), 125.9-140.5(\mathrm{Ar}-\mathrm{C}), 63.78$ $(\mathrm{CH}), 43.30\left(\mathrm{CH}_{2}\right), 30.3\left(\mathrm{CH}_{3}\right)$.

\section{References}

[1] W.B. Geiger, J.E. Conn, J. Am. Chem. Soc. 67 (1945) 112-116;

[2] S. Ambekar, S.S. Venekar, S. Acharya, S. Rajagopal, J. Pharm. Pharmacol.13 (1961) 698-699.

[3] W. Cole, P.L. Julian, J. Org. Chem. 19 (1954) 131-138

[4] L. Main, K.B. Old, Tetrahedron Lett. (1977) 2809-2810.

[5] ElShora AI. Crystal and molecular structure of 3-hydrazino-1hydrazinothio-carbonyl pyrazoline (TNT3). Egypt J Sol. 2000; 23:251-254

[6] Sobhia HR, Yaminib Y, Esrafili A, Adiba M. Extraction and determination of 2-pyrazoline derivatives using liquid phase microextraction based on solidification of floating organic drop. J Pharm Biomed Anal. 2008; 45:316-320.

[7] Nauduri D, Reddy GB, Chem.: Synthesis and activity of 2pyrazoline derivatives. Pharm. Bull. Tokyo, 1998; 46: 1254.

[8] Korgaokar SS, Patil PH, Shah MT, Parekh HH, Studies on Pyrazolines: Preparation and antimicrobial activity of 3-(3'(pchlorophenylsulphonamidophenyl)-5-aryl-acetyl pyrazolines.Indian J. Pharm. Sci. 1996;58: 222.

[9] Udupi RH, Kushnoor AR, Bhat AR Synthesis and biological evaluation of certain pyrazoline derivative of 2-(6methoxynaphthyl)-propionic acid.Indian J. Heterocyclic Chem. 1998; 8:63.

[10] Delay F (S.AFermeinch) Patentschriff (Switz), C.A. 1992; 117:90276f.

[11] Geigy JR, Belg, 466668, Aug.31, 1942; C.A., 1945; 39:7848.

[12] Reddy DB, Senshama T, Ramma Reddy BMV, Indian J. Chem. 1991:30(B), 46

[13] Zalgislaw K. Zbigniew, Acta .Pol Pharm, 1979; 36(6), 645:C.A., 1980; 93:204525e

[14] Yamashita, Hiroyuti, Odata Mocoto, Kawazara Hirahi and NamekawaHiroshi; Eur.Patent appl.Ep1988; 295695CL.Co7D401/6) J. $\quad$ P. Appl.,1987;87/148919,C.A 1989;111:2351

[15] Bauer A.N., Kirby W.N.M., Sherries J.C., Truck M.: Am. J. Clin. Pathol. 45, 493 (1996).

[16] M. M. Kamel et al., Dyes and Pigments, 65 (2005) 103

[17] S. M. Zhou et al., J. Solid State Chem., 178 (2005) 399.

[18] W. Bonrath., UltrasonicsSonochemistry, 12 (2005) 103.

[19] M. W. A. Kuijpers et al., Polymer, 45 (2004) 6461.

[20] A. Fürstner and I. Konetzki., Tetrahedron Letters, 39 (1998) 5721.

[21] (a) K. Suslick., S. Science, 247 (1990) 1439. (b) T. Mason.J. Chem Soc. Rev., 26 (1997) 443. (c) G. Cravotto and P. Cintas., Chem. Soc. Rev., 35 (2006) 180.

[22] H. Fillion, J. L. Luche., In Synthetic Organic Sonochemistry. Luche, J.L., Ed, Plenum: New York, NY, (1998).

[23] D. H. Bremmer., UltrasonicsSonochemistry, 1 (1994) 119

[24] J. L. Luche., C. R. Acad., Sci. Paris., 323 (1996) 337.

[25] F Grieser and M Ashokkumar ., F Caruso (Ed.), Wiley-VCH GmbH \& Co. KgaA, Weinheim, (2004) 120

[26] A. C. Barton et al., Biosensors and Bioelectronics, 20 (2004) 328.

[27] (a) D. Peters, J. Mater. Chem., 6 (1996) 1605, (b) K. S. Suslinck and G. Price., J. Аnпи. Rev. Mater. Sci., 29 (1999) 295, (c) A. Gedanken., Ultrason. Sonochem., 11 (2004) 47.

[28] (a) C. M. Sehgal and S. Y. Wang., J. Am. Chem. Soc., 103 (1981) 6606, (b) D. J Donaldson, M.D. Farrington and P. Kruss., J. Phys. Chem., 83 (1979) 3130.

[29] K. S. Suslick, D. A. Hammerton and R. E. Cline, J. Am. Chem Soc., 108 (1986) 5641, (b) E.B. Flint and K. S. Suslick, Science, 253 (1991) 1397.
[30] In: Microbiological assays and tests, Indian Pharmacopoeia, Ministry of Health and Family Welfare, The Controller of Publications, New Delhi, A-100 (1996).

[31] H.W. Seely and P. J. Van Demark., A Laboratory Manual of Microbiology, Taraporewala Sons and Co., Mumbai, 55 (1975).

[32] A. L. Barry., The antimicrobial susceptibility test. Principle and Practice, Lea and Febiger, Philadelphia, 180 (1976). 